Journal of Mathematics and Statistics 7 (4): 343-347, 2011

ISSN 1549-3644

(C) 2011 Science Publications

\title{
Constrained Probabilistic Economic Order Quantity Model under Varying Order Cost and Zero Lead Time Via Geometric Programming
}

\author{
${ }^{1}$ Kotb Abd-El-Hamid Mahmoud Kotb and ${ }^{2}$ Huda Mohamed Hamid Al-Shanbari \\ ${ }^{1}$ Department of Mathematics and Statistics, Faculty of Science, \\ Taif University, Taif, Saudi Arabia \\ ${ }^{2}$ Department of Statistics, Faculty of Science, \\ Princess Nora University for Women, Riyadh, Saudi Arabia
}

\begin{abstract}
Problem statement: In this study, we provide a simple method to determine the inventory policy of probabilistic single-item Economic Order Quantity (EOQ) model, that has varying order cost and zero lead time. The model is restricted to the expected holding cost and the expected available limited storage space. Approach: The annual expected total cost is composed of three components (expected purchase cost, expected ordering cost and expected holding cost. The problem is then solved using a modified Geometric Programming method (GP). Results: Using the annual expected total cost to determine the optimal solutions, number of periods, maximum inventory level and minimum expected total cost per period. A classical model is derived and numerical example is solved to confirm the model. Conclusion/Recommendations: The results indicated the total cost decreased with changes in optimal solutions. Possible future extension of this model was include continuous decreasing ordering function of the number of periods and introducing expected annual demand rate as a decision variable.
\end{abstract}

Key words: Inventory model, holding costs, storage area, lead time, geometric programming, Economic Order Quantity (EOQ), limited storage space, probabilistic single-item, varying order

\section{INTRODUCTION}

The simple EOQ model is the most fundamental of all inventory models. It is assumed that the expected order cost and demand rate are constants. Fabrycky and Banks (1967) studied some probabilistic models of the case, where both demand and procurement lead time are identically and independently rodmen variables distributed. Discussed a simple method for determining order quantities in joint replenishment of deterministic demand. Unconstrained probabilistic inventory problem with constant cost units has been treated. Ben-Daya et al. (2006) presented integrated inventory control and inspection policies with deterministic demand. Also, Abou-El-Ata and Kotb (1997) developed a crisp inventory model under two restrictions. Teng and Yang (2007) studied deterministic inventory lot-size models with time-varying demand and cost under generalized holding costs. Other related studies are presented by Hadly and Whitin (1963); Cheng (1989); Jung and Klein (2001); Das et al. (2000) and Mandal et al. (2006). An optimal inventory policy for items having linear demand and variable deterioration rate with trade credit has been discussed by Sarbjit and Raj (2010). Recently, EL-Sodany (2011) presented periodic review probabilistic inventory system with zero lead time under constraint and varying holding cost. Also, Kotb and Fergany (2011) discussed multi-item EOQ model with varying holding cost: a geometric programming approach.

In this study, we have proposed constrained probabilistic single-item EOQ model with varying order cost and zero lead time. The varying order cost is continually increasing function of number of periods per inventory cycle. The constraints are proposed to be the expected holding cost and the expected available limited storage space. The optimal number of periods, the optimal maximum inventory level and the minimum expected total cost per period are obtained using a modified geometric programming method. Finally, a numerical example is used to confirm the results.

Assumptions and notations: The following assumptions are made for developing the model:

Corresponding Author: Kotb Abd-El-Hamid Mahmoud Kotb, Department of Mathematics and Statistics, Faculty of Science, Taif University, Taif, Saudi Arabia Tel: 00966500655657 Fax: 0096627362105 
- Demand rate is random variable having a known probability distribution

- Lead time is zero

- Shortages are not allowed

- Review of the stock level is made every ${ }_{N}$ period

- Ordering cost $\mathrm{C}_{0}(\mathrm{~N})=\alpha+\beta \mathrm{N}, \quad \alpha>0, \beta \geq 0 \quad \mathrm{i}$ is continuous increasing function of the number of periods. Where $\alpha$ and $\beta$ are real constants selected to provide the best fit of the estimated cost function

- The minimization of the expected total cost is the objective

In addition, the following notation is adopted for developing the model:

$\mathrm{C}_{\mathrm{h}} \quad=$ Holding cost.

$\mathrm{C}_{\mathrm{p}} \quad=$ Purchase cost.

$\mathrm{C}_{\mathrm{o}} \quad=$ Ordering cost.

$\mathrm{C}_{\mathrm{o}}(\mathrm{N})=$ Varying order cost per period.

$\overline{\mathrm{D}} \quad=$ Expected annual demand rate.

$\mathrm{K}_{1} \quad=$ Limitation on the expected holding cost.

$\mathrm{K}_{2}=$ Limitation on the storage area.

$\mathrm{N} \quad=$ Number of periods.

$\mathrm{N}^{*} \quad=$ Optimal number of periods.

$\mathrm{Q}_{\mathrm{m}} \quad=$ Maximum inventory level.

$\mathrm{Q}^{*}{ }_{\mathrm{m}} \quad=$ Optimal maximum inventory level.

$\mathrm{S}=$ Available storage area .

$\overline{\mathrm{TC}}=$ Expected total cost.

Model formulation and analysis: The annual expected total cost is composed of three components (expected purchase cost, expected ordering cost and expected holding cost) according to the basic assumptions and notation of the EOQ model provided by Eq. 1 Fabrycky and Banks (1967):

$\overline{\mathrm{TC}}=\mathrm{C}_{\mathrm{p}} \overline{\mathrm{D}}+\frac{\mathrm{C}_{\mathrm{o}}(\mathrm{N})}{\mathrm{N}}+\frac{\mathrm{C}_{\mathrm{h}} \overline{\mathrm{D}}[2 \mathrm{v}+\mathrm{N}]}{2}$

The restrictions on the expected holding cost and the expected storage area are the following two conditions Eq. 2:

$\frac{\mathrm{C}_{\mathrm{h}} \overline{\mathrm{D}} \mathrm{N}}{2} \leq \mathrm{K}_{1}$ and $\mathrm{S} \overline{\mathrm{D}} \mathrm{N} \leq \mathrm{K}_{2}$

In order to solve this primal function which is a convex programming problem, it can be rewritten in the following form Eq. 3 and 4: $\min \overline{\mathrm{TC}}=\mathrm{C}_{\mathrm{p}} \overline{\mathrm{D}}+\frac{\alpha}{\mathrm{N}}+\beta+\mathrm{C}_{\mathrm{h}} \overline{\mathrm{D} v}+\frac{\mathrm{C}_{\mathrm{h}} \overline{\mathrm{D} N}}{2}$

Subject to:

$\frac{\mathrm{C}_{\mathrm{h}} \overline{\mathrm{D}} \mathrm{N}}{2 \mathrm{~K}_{1}} \leq 1$ and $\frac{\mathrm{S} \overline{\mathrm{D}} \mathrm{N}}{\mathrm{K}_{2}} \leq 1$

The term $C_{p} \bar{D}+\beta+C_{h} \bar{D} v$ is constant and hence can be ignored.

Applying Duffin et al. (1967) results of geometric programming technique on (3) and (4), the enlarged predual function can be written in the form Eq. 5:

$$
\begin{aligned}
& \mathrm{G}(\underline{\mathrm{W}})=\left(\frac{\alpha}{\mathrm{NW}_{1}}\right)^{\mathrm{W}_{1}}\left(\frac{\mathrm{C}_{\mathrm{h}} \overline{\mathrm{D} N}}{2 \mathrm{~W}_{2}}\right)^{\mathrm{W}_{2}}\left(\frac{\mathrm{C}_{\mathrm{h}} \overline{\mathrm{D} N}}{2 \mathrm{~K}_{1} \mathrm{~W}_{3}}\right)^{\mathrm{W}_{3}}\left(\frac{\mathrm{S} \overline{\mathrm{D}} \mathrm{N}}{\mathrm{K}_{2} \mathrm{~W}_{4}}\right)^{\mathrm{W}_{4}} \\
&=\left(\frac{\alpha}{\mathrm{W}_{1}}\right)^{\mathrm{W}_{1}}\left(\frac{\mathrm{C}_{\mathrm{h}} \overline{\mathrm{D}}}{2 \mathrm{~W}_{2}}\right)^{\mathrm{W}_{2}}\left(\frac{\mathrm{C}_{\mathrm{h}} \overline{\mathrm{D}}}{2 \mathrm{~K}_{1} \mathrm{~W}_{3}}\right)^{\mathrm{W}_{3}}\left(\frac{\mathrm{S} \overline{\mathrm{D}}}{\mathrm{K}_{2} \mathrm{~W}_{4}}\right)^{\mathrm{W}_{4}} \\
& \times \mathrm{N}^{-\mathrm{w}_{1}+\mathrm{w}_{2}+\mathrm{w}_{3}+\mathrm{w}_{4}}
\end{aligned}
$$

where, $\underline{\mathrm{W}}=\mathrm{W}_{\mathrm{j}}, \mathrm{J}=1,2,3,4\left(0<\mathrm{W}_{\mathrm{j}}<1\right.$, $)$ are the weights and could be easily deduced from Equation 5 through the use of the following normal and orthogonal conditions Eq. 6:

$\left.\begin{array}{c}\mathrm{W}_{1}+\mathrm{W}_{2}=1 \\ \text { and } \\ -\mathrm{W}_{1}+\mathrm{W}_{2}+\mathrm{W}_{3}+\mathrm{W}_{4}=0\end{array}\right\}$

These are two linear equations in four unknowns having an infinite number of solutions. However, the problem is to select the optimal solution of the weights $\mathrm{W}_{\mathrm{j}}^{*}, 0<\mathrm{W}_{\mathrm{j}}^{*}<1, \mathrm{~J}=1,2,3,4$.

By solving Eq. 6, we have Eq. 7:

$\left.\begin{array}{l}\mathrm{W}_{1}=\frac{1+\mathrm{W}_{3}+\mathrm{W}_{4}}{2} \\ \text { and } \\ \mathrm{W}_{2}=\frac{1-\mathrm{W}_{3}-\mathrm{W}_{4}}{2}\end{array}\right\}$

Substituting $\mathrm{W}_{1}$ and $\mathrm{W}_{2}$ in Eq. 5 , then the dual function is Eq. 8: 


$$
\begin{aligned}
& \mathrm{g}\left(\mathrm{W}_{3}, \mathrm{~W}_{4}\right)=\left(\frac{2 \alpha}{1+\mathrm{W}_{3}+\mathrm{W}_{4}}\right)^{\frac{1+\mathrm{W}_{3}+\mathrm{W}_{4}}{2}}\left(\frac{\mathrm{C}_{\mathrm{h}} \overline{\mathrm{D}}}{1-\mathrm{W}_{3}-\mathrm{W}_{4}}\right)^{\frac{1+\mathrm{W}_{3}+\mathrm{W}_{4}}{2}} \\
& \left(\frac{\mathrm{C}_{\mathrm{h}} \overline{\mathrm{D}}}{2 \mathrm{~K}_{1} \mathrm{~W}_{3}}\right)^{\mathrm{W}_{3}}\left(\frac{\mathrm{S} \overline{\mathrm{D}}}{\mathrm{K}_{2} \mathrm{~W}_{4}}\right)^{\mathrm{W}_{4}}
\end{aligned}
$$

In order to find the optimal $\mathrm{W}_{3}$ and $\mathrm{W}_{4}$ which maximize $\mathrm{g}\left(\mathrm{W}_{3}, \mathrm{~W}_{4}\right)$, the logarithm of both side of Eq. 8 and the partial derivatives were taken relative to $\mathrm{W}_{3}$ and $\mathrm{W}_{4}$, respectively. Setting each of them to equal zero and simplifying, we get Eq. 9 and 10:

$$
\left(\frac{2 \alpha}{\mathrm{C}_{\mathrm{h}} \overline{\mathrm{D}}}\right)\left(\frac{1-\mathrm{W}_{3}-\mathrm{W}_{4}}{1+\mathrm{W}_{3}+\mathrm{W}_{4}}\right)\left(\frac{\mathrm{C}_{\mathrm{h}} \overline{\mathrm{D}}}{2 \mathrm{eK}_{1} \mathrm{~W}_{3}}\right)^{2}=1
$$

and:

$$
\left(\frac{2 \alpha}{C_{h} \bar{D}}\right)\left(\frac{1-W_{3}-W_{4}}{1+W_{3}+W_{4}}\right)\left(\frac{S \bar{D}}{e_{2} W_{4}}\right)^{2}=1
$$

Multiplying relation (9) by the inverse of relation (10), we find Eq. 11:

$$
\frac{\mathrm{W}_{3}}{\mathrm{~W}_{4}}=\frac{\mathrm{C}_{\mathrm{h}} \mathrm{K}_{2}}{2 \mathrm{SK}_{1}}
$$

Substituting $\mathrm{W}_{3}$ and $\mathrm{W}_{4}$ into relations (9) and (10), respectively, we have Eq. 12:

$$
\mathrm{f}_{\mathrm{i}}\left(\mathrm{W}_{\mathrm{j}}\right)=\mathrm{W}_{\mathrm{j}}^{3}+\mathrm{C}_{\mathrm{i}} \mathrm{W}_{\mathrm{j}}^{2}+\mathrm{B}_{\mathrm{i}} \mathrm{W}_{\mathrm{j}}-\mathrm{B}_{\mathrm{i}} \mathrm{C}_{\mathrm{i}}=0, \mathrm{j}=3,4, \mathrm{i}=1,2
$$

Where:

$$
\begin{aligned}
& \mathrm{B}_{1}=\frac{\alpha \mathrm{C}_{\mathrm{h}} \overline{\mathrm{D}}}{2 \mathrm{e}^{2} \mathrm{~K}_{1}^{2}}, \mathrm{~B}_{2}=\frac{2 \alpha \mathrm{S}^{2} \overline{\mathrm{D}}}{\mathrm{e}^{2} \mathrm{C}_{\mathrm{h}} \mathrm{K}_{2}^{2}} \\
& \mathrm{C}_{1}=\frac{\mathrm{C}_{\mathrm{h}} \mathrm{K}_{2}}{\mathrm{C}_{\mathrm{h}} \mathrm{K}_{2}+2 \mathrm{SK}_{1}} \mathrm{C}_{2}=\frac{2 \mathrm{SK}_{1}}{\mathrm{C}_{\mathrm{h}} \mathrm{K}_{2}+2 \mathrm{SK}_{1}}
\end{aligned}
$$

It is clear that $f_{i}(0)<0$ and $f_{i}(1)>0, i=1,2$, which means that there exists a root $\mathrm{W}_{\mathrm{j}} \varepsilon(0,1), \mathrm{j}=3,4$. The trial and error approach can be used to find these roots. However, we shall first verify any $\operatorname{root} \mathrm{W}^{*}, \mathrm{j}=3,4$ calculated from Eq. 12 to maximize $f_{i}\left(W_{j}\right), I=1,2, j=$ 3,4 , respectively. This was confirmed by the second derivative to $\ln \mathrm{g}\left(\mathrm{W}_{3}, \mathrm{~W}_{4}\right)$ with respect to $\mathrm{W}_{3}$ and $\left.\mathrm{W}_{4}\right)$, respectively, which is always negative.

Thus, the roots $\mathrm{W}_{3}{ }_{3}$ and $\mathrm{W}_{4}{ }_{4}$ calculated from Eq. 12 maximize the dual function $\mathrm{g}\left(\mathrm{W}_{3}, \mathrm{~W}_{4}\right)$. Hence, the optimal solutions are $\mathrm{W}_{3}^{*}$ and $\mathrm{W}_{4}^{*}$ of Eq. 12, respectively. $\mathrm{W}_{1}^{*}$ and $\mathrm{W}^{*}{ }_{2}$ are evaluated by substituting the value of $\mathrm{W}_{3}^{*}$ and $\mathrm{W}_{4}^{*}$ in expression (7).

To find the optimal number of periods $\mathrm{N}^{*}$ and the optimal maximum inventory level $\mathrm{Q}_{\mathrm{m}}{ }^{*}$, we applied the results of Duffin et al. (1967) for geometric programming as indicated blow:

$\frac{\alpha}{N^{*}}=W_{1}^{*} g\left(W_{3}^{*}, W_{4}^{*}\right)$ and $\frac{C_{\mathrm{h} \overline{\mathrm{DN}}}}{2}=\mathrm{W}_{2}^{*} \mathrm{~g}\left(\mathrm{~W}_{3}^{*}, \mathrm{~W}_{4}^{*}\right)$

By solving these relations, the optimal number of periods is given by Eq. 13:

$$
\mathrm{N}^{*}=\sqrt{\frac{2 \alpha \mathrm{W}_{2}^{*}}{\mathrm{C}_{\mathrm{h}} \overline{\mathrm{D}} \mathrm{W}_{1}^{*}}}=\sqrt{\frac{2 \alpha\left(1-\mathrm{W}_{3}^{*}-\mathrm{W}_{4}^{*}\right)}{\mathrm{C}_{\mathrm{h}} \overline{\mathrm{D}}\left(1+\mathrm{W}_{3}^{*}+\mathrm{W}_{4}^{*}\right)}}
$$

and the optimal maximum inventory level $\mathrm{Q}^{*}{ }_{\mathrm{m}}$ is Eq. 14:

$$
\mathrm{Q}_{\mathrm{m}}^{*}=\overline{\mathrm{D}} \mathrm{N}^{*} \mathrm{~g}\left(\mathrm{~N}^{*}\right)=\overline{\mathrm{D}} \mathrm{v}+\sqrt{\frac{2 \alpha \overline{\mathrm{D}}\left(1-\mathrm{W}_{3}^{*}-\mathrm{W}_{4}^{*}\right)}{\mathrm{C}_{\mathrm{h}}\left(1+\mathrm{W}_{3}^{*}+\mathrm{W}_{4}^{*}\right)}}
$$

By substituting the value of $\mathrm{N}^{*}$ in relation (3), we get the minimum expected total cost as Eq. 15:

$$
\min \overline{\mathrm{TC}}=\beta+\left(\mathrm{C}_{\mathrm{p}}+\mathrm{v} \mathrm{C}_{\mathrm{h}}\right) \overline{\mathrm{D}}+\sqrt{\frac{\alpha \mathrm{C}_{\mathrm{h}} \overline{\mathrm{D}}}{\left.2 \mathrm{~W}_{1}^{*} \mathrm{~W}_{2}^{*}\right)}}
$$

As a special case, we assume $\beta=0$ and $\mathrm{k}_{\mathrm{i}} \rightarrow \infty \Rightarrow$ $\mathrm{C}_{\mathrm{o}}(\mathrm{N}), \mathrm{I}=1,2$. This is the probabilistic single-item inventory model with constant order cost and without any restrictions, which is consistent with the results of Fabrycky and Banks (1967).

An illustrative example: The decision variables (the optimal number of periods $\mathrm{N}^{*}$ and the optimal maximum inventory level $\mathrm{Q}_{\mathrm{m}}{ }^{*}$ ) should be computed to minimize the annual relevant expected total cost. Assume the parameters of the inventory model as:

$$
\begin{aligned}
& C_{o}=\$ 11 \text { per procurement, } \\
& C_{h}=\$ 0.05 \text { per unit per period, } C_{p}=\$ 25 \text { per unit }
\end{aligned}
$$


J. Math. \& Stat., 7 (4): 343-347, 2011

Table 1: The optimal results of different values of $\alpha$ and $\beta$

\begin{tabular}{|c|c|c|c|c|c|c|c|c|c|c|c|c|}
\hline \multirow{2}{*}{$\begin{array}{l}\beta \\
\alpha\end{array}$} & \multicolumn{5}{|c|}{$\mathrm{C}_{\mathrm{o}}\left(\mathrm{N}^{*}\right)$} & \multicolumn{5}{|l|}{$\min \overline{\mathrm{TC}}$} & \multirow[b]{2}{*}{$\mathrm{N}^{*}$} & \multirow[b]{2}{*}{$\mathrm{Q}_{\mathrm{m}}{ }^{*}$} \\
\hline & 0 & 10 & 20 & 50 & 100 & 0 & 10 & 20 & 50 & 100 & & \\
\hline 1 & 1 & 27.347 & 53.694 & 132.737 & 264.473 & 50.811 & 60.811 & 70.811 & 100.811 & 150.811 & 2.6340 & 11.269 \\
\hline 2 & 2 & 34.095 & 66.190 & 162.477 & 322.954 & 51.083 & 61.083 & 71.083 & 101.083 & 151.083 & 3.2090 & 12.419 \\
\hline 5 & 5 & 44.613 & 84.227 & 203.068 & 401.135 & 51.760 & 61.760 & 71.760 & 101.760 & 151.760 & 3.9610 & 13.922 \\
\hline 8 & 8 & 51.066 & 94.133 & 223.332 & 438.665 & 52.372 & 62.372 & 72.372 & 102.372 & 152.372 & 4.3060 & 14.613 \\
\hline 10 & 10 & 54.546 & 99.093 & 232.733 & 455.466 & 52.767 & 62.767 & 72.767 & 102.768 & 152.768 & 4.4540 & 14.909 \\
\hline 15 & 15 & 61.925 & 108.851 & 249.629 & 484.257 & 53.731 & 63.731 & 73.731 & 103.731 & 153.731 & 4.6920 & 15.385 \\
\hline 30 & 30 & 80.009 & 130.020 & 280.049 & 530.098 & 56.548 & 66.548 & 76.548 & 106.549 & 156.549 & 5.0009 & 16.002 \\
\hline 50 & 50 & 101.546 & 153.092 & 307.731 & 565.462 & 60.258 & 70.257 & 80.257 & 110.258 & 160.258 & 5.1540 & 16.309 \\
\hline 100 & 100 & 152.862 & 205.724 & 364.310 & 628.621 & 69.481 & 79.481 & 89.481 & 119.481 & 169.481 & 5.2860 & 16.572 \\
\hline 200 & 200 & 253.585 & 307.171 & 467.927 & 735.853 & 87.891 & 97.891 & 107.892 & 137.892 & 187.892 & 5.3580 & 16.717 \\
\hline 500 & 500 & 554.044 & 608.087 & 770.218 & 1040.440 & 143.088 & 153.088 & 163.088 & 193.088 & 243.088 & 5.4040 & 16.808 \\
\hline
\end{tabular}

$\overline{\mathrm{D}}=2$ unit per period, $\mathrm{S}=50$ cubic unit per item, $\mathrm{v}=3$

$\mathrm{K}_{1}=\$ 1000$ per unit and $\mathrm{K}_{2}=200$ cubic units of space

The Optimal results of different values of $\alpha$ and $\beta$ are shown in Table 1.

\section{CONCLUSION}

This work investigated how ordering cost function, two constraints and geometric programming approach affect the probabilistic EOQ model. Ordering cost function was assumed to depend on number of periods. In addition, the constraints were expected holding cost and expected available limited storage space. A geometric programming approach was devised to determine the optimal solution for probabilistic EOQ, number of periods, maximum inventory level and minimum expected total cost per period instead of the traditional Lagrangian method. Finally, a classical model is derived and numerical example is solved to confirm the model. The results indicated that the total cost decreased with changes in $\alpha, \beta, \mathrm{N}^{*}$ and $\mathrm{Q}_{\mathrm{m}}{ }^{*}$. Possible future extension of this work was include continuous decreasing ordering function of the number of periods and introducing expected annual demand rate as a decision variable.

\section{REFERENCES}

Abou-EL-Ata, M.O. and K.A.M. Kotb, 1997. Multiitem EOQ inventory model with varying holding cost under two restrictions: A geometric programming approach. Product. Plann. Control, 8: 608-611.

Ben-Daya, M., S.M. Noman and M. Hariga, 2006. Integrated inventory control and inspection policies with deterministic demand. Comput. Operat. Res., 33: 1625-1638. DOI: 10.1016/j.cor.2004.11.010
Cheng, T.C.E., 1989. An economic order quantity model with demand-dependent unit cost. Eur. J. Operat. Res., 40: 252-256. DOI: 10.1016/03772217(89)90334-2

Das, K., T.K. Roy and M. Maiti, 2000. Multi-item inventory model with quantity-dependent inventory costs and demand-dependent unit cost under imprecise objective and restrictions: A geometric programming approach. Product. Plann. Control, 11: 781-788. DOI: 10.1080/095372800750038382

Duffin, R.J., E.L. Peterson and C.M. Zener, 1967. Geometric Programming: Theory and Application. 1st Edn., John Wiley and Sons, New York, ISBN: 0471223700, pp: 278.

EL-Sodany, N. H., 2011. Periodic review probabilistic multi-item inventory system with zero lead time under constraint and varying holding cost. J. Math. Stat., 7: 12-19. DOI: 10.3844/jmssp.2011.12.19

Fabrycky, W.J. and J. Banks, 1967. Procurement and Inventory Systems: Theory and Analysis. 1st Edn., Reinhold Publishing Corporation, USA., ISBN-10: 0278917399, pp: 256.

Hadly, G. and T.M. Whitin, 1963. Analysis of Inventory Systems. 1st Edn., Prentice-Hall, Englewood Cliffs, New Jersey, ISBN-10: 0130329533, pp: 528.

Jung, H. and C.M. Klein, 2001. Optimal inventory policies under decreasing cost functions via geometric programming. Eur. J. Operat. Res., 132: 628-642. DOI: 10.1016/S0377-2217(00)00168-5

Kotb, K.A.M. and H.A. Fergany, 2011. Multi-Item EOQ model with varying holding cost: A geometric programming approach. Int. Math. Forum, 6: 1135-1144.

Mandal, N.K. T.K. Roy and M. Maiti, 2006. Inventory model of deteriorated items with a constraint: A geometric programming approach. Eur. J. Operat. Res., 173: 199-210. DOI: 10.1016/j.ejor.2004.12.002 
Sarbjit, S. and S.S. Raj, 2010. A stock dependent economic order quantity model for perishable items under inflationary conditions. Am. J. Econ.

Bus. Admin., 2: 317-322. DOI: 10.3844/ajebasp.2010.317.322
Teng, J.T. and H.L. Yang, 2007. Deterministic inventory lot-size models with time-varying demand and cost under generalized holding costs. Inform. Manage. Sci., 18: 113-125. 